\title{
0956 - Transforming Care to treat the changing face of Gestational Diabetes
}

\author{
N. Mahmood, F. Farook, H. El Shafey Mohammed and B. Salih \\ Corniche Hospital, Abu Dhabi, UAE .
}

\section{Background}

In the UAE $20 \%$ of the adult population has type 2 Diabetes. This naturally translates into an increased prevalence of Gestational Diabetes. Corniche Hospital in Abu Dhabi is a major maternity Hos pital in the UAE with 8,000 deliveries/annum. A dedicated Diabetic clinic has been a vailable in the hospital for pregnant diabetic women since 1997.

We had recognized two major problems in our population.

Mild Gestational Diabetics had adverse pregnancy outcomes.

Diabetics were being missed because of risk based screening.

In 2010 when the IADPSG trie d to unify the method for the diagnosis of gestational Diabetes world wide, we at Corniche adopted the recommendations in the ir entire ty hoping our patients would benefit from the lower diagnostic thre sholds. We also implemented Universal Screening for all pregnant ladies registering the ir pregnancies at Corniche.

\section{Aim}

To identify cases of Gestational Diabetes which were being missed due to risk based screening and to improve Pregnancy Outcomes as the diagnostic thresholds and glycaemic targets were lower than we were previously using in our Hospital.

\section{Glycemic Targets}

Fasting Glucose

2 Hours Postprandial Glucose

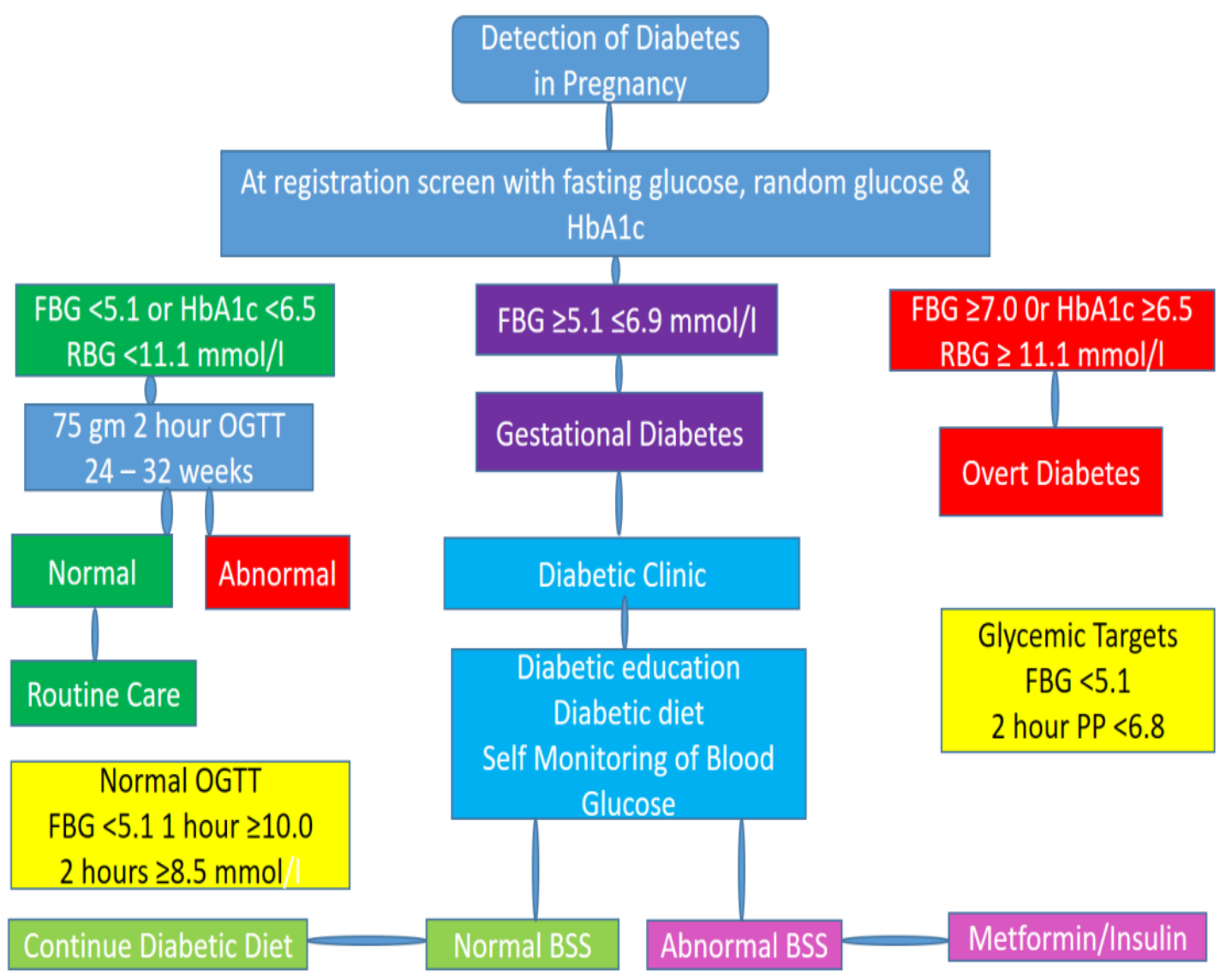

\section{Criteria}

Screening

OGTT

Fasting Plasma Glucose

1 Hour Post Glucose

2 hour Post Glucose

Gestational Diabetes

Overt Diabetes

\begin{tabular}{|c|c|}
\hline Pre IADPSG & Post IADPSG \\
\hline$<5.3$ & $<5.1$ \\
$<7.0$ & $<6.7$
\end{tabular}

6.7
Pregnant Women with Diabetes in 2013

\begin{tabular}{ll} 
Total Diabetic Women & 1503 \\
\hline Gestational Diabetes & $1288(86 \%)$ \\
\hline Overt & $2 \%($ undiagnosed type 2) \\
\hline Pre-Existing Diabetes & $12 \%$
\end{tabular}

\begin{tabular}{|c|c|c|}
\hline Mothers of babies in NICU & $\mathbf{2 0 1 1}(\%)$ & $\mathbf{2 0 1 3}(\%)$ \\
\hline GDM on Diet & 49.3 & 37.05 \\
\hline GDM on Insulin & 14.0 & 7.17 \\
\hline GDM on Metformin & 16.9 & 25.50 \\
\hline GDM on Metformin \& Insulin & & 8.76 \\
\hline
\end{tabular}

Method

Pros pective Observational Study

All women registering a new pregnancy in Corniche Hospital from $2^{\text {nd }}$ January 2012 were screened for overt diabetes at the first visit. A random blood glucose and a glycosylated Haemoglobin was requested as part of the booking bloods. A fasting glucose was requested on a subsequent vis it.

Non pregnant criteria were used to identify previously undiagnosed type 2 Diabetes. FPG $\geq 7.0 \mathrm{mmol} / \mathrm{L}$ or $\mathrm{HbA} 1 \mathrm{C} \geq 6.5 \%$ or

Random plasma glucose $\geq 11.1 \mathrm{mmol} / \mathrm{L}$ Confirmed by FPG or HbA1C We collected data for a cohort of women who were diagnosed as Gestational Diabetes and de livered their babies in 2013.

We collated this with the Neonatal unit's data on babies of diabetic mothers and looked at the impact of the IADPSG criteria on neo natal outcomes.

\begin{tabular}{|c|c|c|}
\hline Fetal Outcome & $2011(136)$ & $2013(251)$ \\
\hline $\begin{array}{c}\text { \%Total N.I.C.U } \\
\text { Admission }\end{array}$ & 14.6 & 25.96 \\
\hline LGA & 22.8 & 11.95 \\
\hline SGA & 28.7 & 10.76 \\
\hline Hypoglycemia & 27.2 & 19.52 \\
\hline Polycythemia & 3.7 & 3.59 \\
\hline Birth Trauma & 0.0 & 0.00 \\
\hline Congenital Anomalies & 30.1 & 10.80 \\
\hline $\begin{array}{l}\text { Asymptomatic } \\
\text { Hypoglycemia }\end{array}$ & 11.8 & 18.73 \\
\hline $\begin{array}{l}\text { Symptomatic } \\
\text { Hypoglycemia }\end{array}$ & 15.4 & 0.80 \\
\hline
\end{tabular}

Dis cus s ion

Our results in 2013 showed a significant impact of adaptation of the IADPS G recommendations on the pregnancy outcome of our GDM cohort. We are aware that varying outcomes have been reported by diffe rent centres around the world.

We are continuing to prospectively collect data on our patient population to see if these outcomes are consistent. 